\title{
Analysis of influential factors in determining very fast transient overvoltages of GIS substations
}

\begin{abstract}
High voltage Gas Insulated Substation (GIS) is threatened by Very Fast Transient Overvoltage (VFTO) which is high amplitude and high frequency transient within the range from $100 \mathrm{kHz}$ up to $50 \mathrm{MHz}$ in power systems. Operation of Disconnecting Switch is the main origin of these overvoltage phenomena that is analyzed in this paper. In this study, the effects of several parameters that influence on VFTO amplitude have been discussed. The focus of this paper is on the VFTO study of "Siah-bishe" power plant 400kV GIS substation. The study was carried out by modeling all pieces of equipment in EMTP-RV and careful consideration of different modeling guidelines and instructions described in available standards.
\end{abstract}

Keyword: Very fast transient (VFT); Very fast transient overvoltage (VFTO); Very fast transient current (VFTC); EMTP; Gas insulated substation (GIS); Disconneting switch operation; Basic insulation level (BIL) 